\title{
Comparison of outcomes between squamous cell carcinoma and adenocarcinoma in patients with surgically treated stage I-II cervical cancer
}

\author{
MAKOTO YAMAUCHI, TAKESHI FUKUDA, TAKUMA WADA, MASARU KAWANISHI, KENJI IMAI, \\ YASUNORI HASHIGUCHI, TOMOYUKI ICHIMURA, TOMOYO YASUI and TOSHIYUKI SUMI
}

Department of Obstetrics and Gynecology, Graduate School of Medicine, Osaka City University, Osaka 545-8585, Japan

Received March 7, 2014; Accepted April 30, 2014

DOI: $10.3892 / \mathrm{mco} .2014 .295$

\begin{abstract}
To improve our understanding of cervical adenocarcinoma (AD) and evaluate the clinical and pathological variables affecting its prognosis, we retrospectively reviewed the medical records of 455 patients with cervical cancer [International Federation of Gynecology and Obstetrics stage I/II; 91 cases with AD and 364 with squamous cell carcinoma (SCC)] who underwent surgery at our hospital between January, 1995 and August, 2012 and compared the characteristics and prognoses between AD and SCC cases, including age, clinical stage, histological type, lymph node metastasis, lymphovascular space invasion (LVSI), cervical stromal invasion, parametrial invasion, vaginal invasion, corpus invasion, ovarian metastasis and tumor diameter. We used Cox regression analysis to determine independent prognostic factors. $\mathrm{AD}$ was found to have a significantly poorer prognosis in all the patients $(\mathrm{P}=0.001)$, stage I patients $(\mathrm{P}=0.001)$ and stage IB patients $(\mathrm{P}<0.05)$. The prognosis did not differ in patients who did not require postoperative treatment; however, patients who received postoperative treatment exhibited a significantly poorer prognosis $(\mathrm{P}<0.05)$. Patients with AD who received postoperative irradiation alone had a significantly poorer prognosis $(\mathrm{P}<0.05)$. The multivariate analysis identified LVSI $(\mathrm{P}=0.008)$, stromal invasion $(\mathrm{P}=0.024)$ and ovarian metastasis $(\mathrm{P}=0.032)$ as independent predictors of shorter survival. AD was associated with a worse prognosis compared to SCC in patients with stage IB disease, particularly in those who required postoperative treatment. Such patients may benefit from individualized postoperative treatments that differ from those applied for SCC.
\end{abstract}

Correspondence to: Dr Takeshi Fukuda, Department of Obstetrics and Gynecology, Graduate School of Medicine, Osaka City University, 1-4-3 Asahimachi, Abeno-ku, Osaka 545-8585, Japan E-mail: takeshif@med.osaka-cu.ac.jp

Key words: cervical carcinoma, squamous cell carcinoma, adenocarcinoma, prognosis

\section{Introduction}

Cervical cancer is a common cause of cancer-related mortality among women worldwide (1). Squamous cell carcinoma (SCC) is the most common histological type of cervical cancer. Although the incidence of cervical cancer has decreased over the last few years, the percentage of cervical adenocarcinoma (AD) has increased and accounts for $20 \%$ of all cervical cancers (2). The introduction of liquid-based cytology and p16 immunostaining may have contributed to this increase, as the detection of atypical glandular cells is reportedly difficult by conventional screening (3-6). The prognostic significance of AD histology remains unclear. It was previously reported that $\mathrm{AD}$ is less curable and associated with a shorter survival compared to SCC (7-11), whereas other studies reported no significant differences in prognosis between $\mathrm{AD}$ and SCC (12-16). Notably, the prognostic implications of applying the same treatment strategies on AD as for SCC have not been extensively investigated.

In this study, we compared the clinicopathological findings and prognoses between surgically treated patients with cervical AD and those with SCC, in order to improve recognition of cervical AD and to evaluate the clinicopathological variables and prognoses of the patients.

\section{Patients and methods}

Patients. The medical records of 455 patients with International Federation of Gynecology and Obstetrics (FIGO) stage I-II cervical AD or SCC who were treated primarily with surgery at Osaka City University Hospital between January, 1995 and August, 2012 were retrospectively reviewed. The 455 patients included 91 with AD and 364 with SCC. The SCC cases included 150 keratinizing and 214 non-keratinizing types; and the AD cases included 57 mucinous ADs, 19 endometrioid ADs, 11 adenosquamous carcinomas, 3 clear-cell carcinomas and 1 poorly differentiated AD.

Data extraction. Inpatient and outpatient medical records were retrospectively reviewed to extract demographic and perioperative data and follow-up information, which included age, FIGO stage, histological type, lymph node status, 

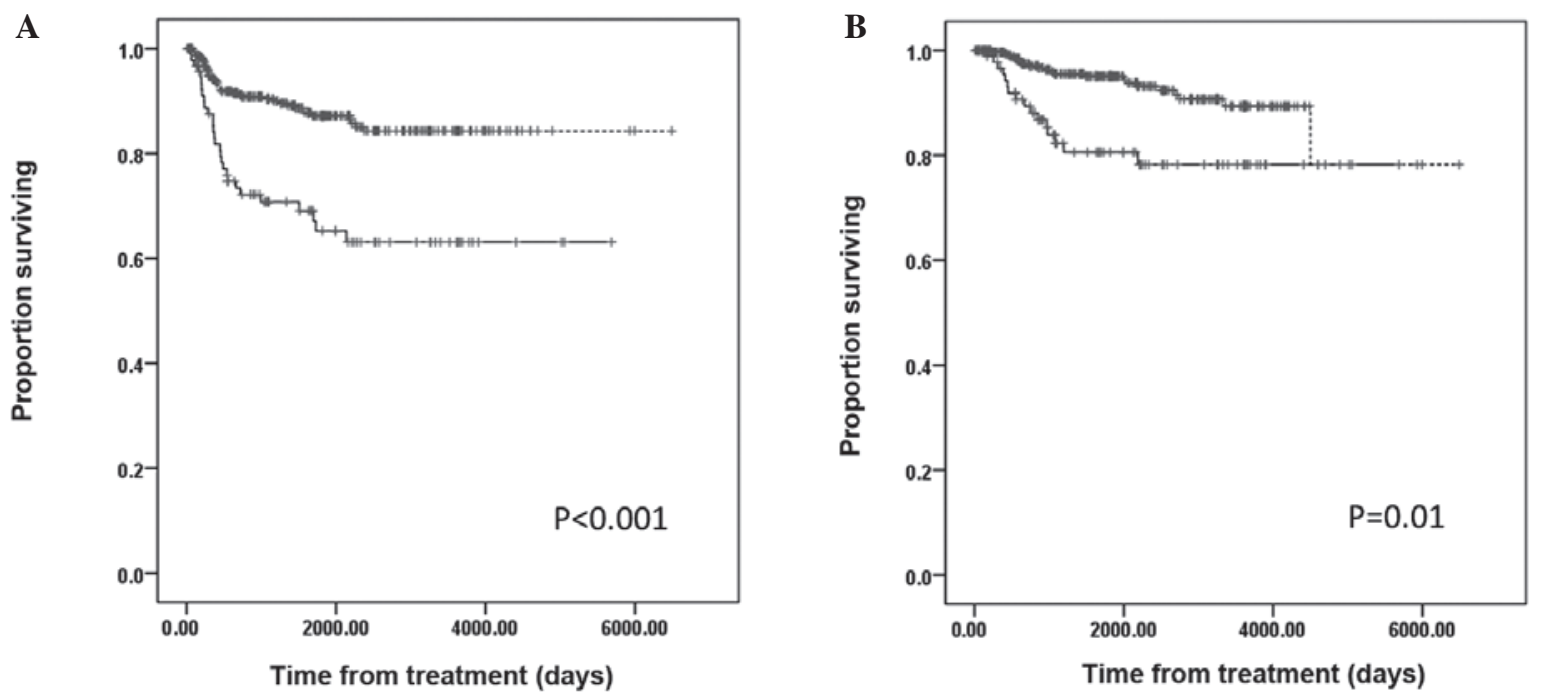

Figure 1. Kaplan-Meier estimates of all the patients. (A) Disease-free survival; and (B) overall survival. Solid line, patients with cervical adenocarcinoma; and dashed line, patients with cervical squamous cell carcinoma.

Table I. Patient characteristics.

\begin{tabular}{|c|c|c|c|}
\hline Characteristics & $\begin{array}{c}\mathrm{AD} \\
\mathrm{n}=91(\%)\end{array}$ & $\begin{array}{c}\text { SCC } \\
\mathrm{n}=364(\%)\end{array}$ & P-value \\
\hline $\begin{array}{l}\text { Age, years } \\
(\text { mean } \pm \text { SD })\end{array}$ & $53.2 \pm 13.2$ & $46.9 \pm 12.7$ & $<0.001$ \\
\hline FIGO stage & & & $<0.001$ \\
\hline IA1 & $5(5.5)$ & $130(35.7)$ & \\
\hline IA 2 & $2(2.2)$ & $8(2.2)$ & \\
\hline IB1 & $45(49.5)$ & $124(34.1)$ & \\
\hline IB2 & $8(8.8)$ & $23(6.3)$ & \\
\hline IIA1 & $0(0)$ & $1(0.02)$ & \\
\hline IIA2 & $0(0)$ & $16(4.4)$ & \\
\hline IIB & $31(34.1)$ & $62(17.0)$ & \\
\hline $\begin{array}{l}\text { Lymph node } \\
\text { metastasis }\end{array}$ & & & NS \\
\hline No & $73(80.2)$ & $317(87.1)$ & \\
\hline Yes & $18(19.8)$ & 47 (12.9) & \\
\hline $\begin{array}{l}\text { Postoperative } \\
\text { treatment }\end{array}$ & $31(34.1)$ & $66(18.1)$ & $<0.001$ \\
\hline CCRT & $6(19.4)$ & $20(30.3)$ & \\
\hline RT & 7 (22.6) & $41(62.1)$ & $<0.001$ \\
\hline $\mathrm{CT}$ & $18(58.1)$ & $5(7.6)$ & \\
\hline Recurrence & & & $<0.001$ \\
\hline No & 68 (74.7) & $324(89.0)$ & \\
\hline Yes & $23(25.2)$ & $40(11.0)$ & \\
\hline
\end{tabular}

$\mathrm{AD}$, adenocarcinoma; SCC, squamous cell carcinoma; NS, not significant; CCRT, concurrent chemoradiotherapy; RT, radiotherapy; CT, chemotherapy.

lymphovascular space invasion (LVSI), cervical stromal invasion, parametrial invasion, vaginal invasion, corpus invasion, ovarian metastasis and tumor size. Stromal invasion depth was classified as either more or less than half the thickness of the cervical wall.

Patients with stage IA1 disease underwent conization and/or abdominal total hysterectomy; those with stage IA 2 or higher disease underwent radical hysterectomy, unless their clinical condition did not allow for this type of intervention. The criteria for postoperative treatment were lymph node metastasis and/or parametrial invasion prior to October, 2007, but were revised in November, 2007, according to the Japan Society of Gynecologic Oncology's treatment guidelines for the Treatment Guidelines for Cervical Cancer (17).

Statistical analysis. Differences between the 2 groups were analyzed with the $\chi^{2}$ test and the Mann-Whitney U test. Survival curves were computed with the Kaplan-Meier method and the significance of each survival difference was determined with the log-rank test. A multivariate analysis with the Cox proportional hazards regression model was performed with each prognostic factor. SPSS software, version 21.0 (IBM, Armonk, NY, USA) was used for data analyses. $\mathrm{P}<0.05$ was considered to indicate a statistically significant difference.

\section{Results}

Patient characteristics. The mean age of the AD group (53.2 years) was higher compared to that of the SCC group (46.9 years; $\mathrm{P}<0.001$; Table I). The two groups differed significantly in the distribution of FIGO stage $(\mathrm{P}<0.001)$, but not in lymph node status. From the total of 97 patients who received postoperative adjuvant treatment, 48 received external irradiation (1.8 Gy daily, 50.4 Gy total, over 5-6 weeks to the pelvic side wall); 23 received cisplatin-based chemotherapy; and 26 received concurrent cisplatin-based chemotherapy and radiotherapy (CCRT). A higher percentage of the AD group received postoperative treatment $(34.1 \%)$ compared to the SCC (18.1\%; $\mathrm{P}<0.001)$. The postoperative regimens differed significantly between the two groups $(\mathrm{P}<0.001)$. Furthermore, the AD group exhibited a higher recurrence rate $(25.2 \%)$ compared to the SCC group $(11.0 \%$; $\mathrm{P}<0.001)$. 

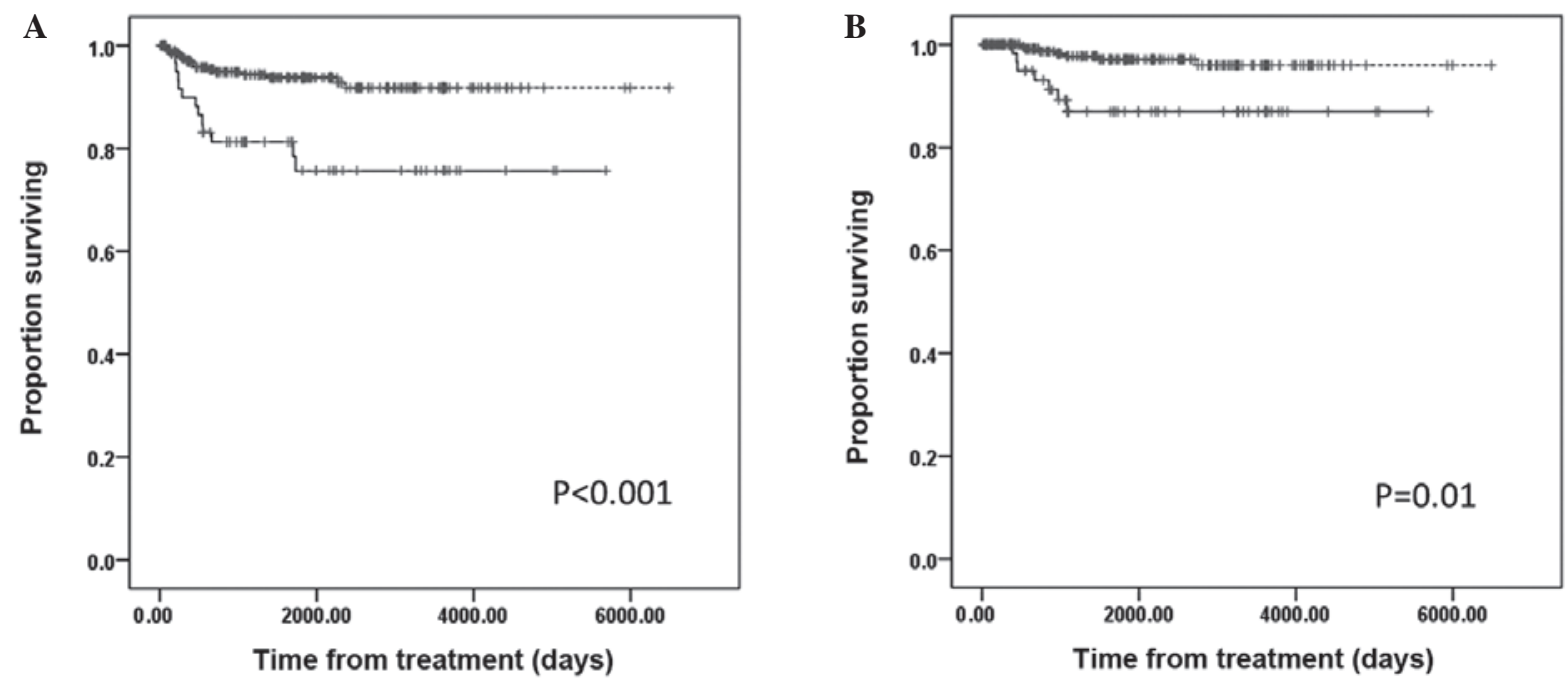

Figure 2. Kaplan-Meier estimates of patients with stage I cervical cancer. (A) Disease-free survival; and (B) overall survival. Solid line, patients with cervical adenocarcinoma; and dashed line, patients with cervical squamous cell carcinoma.
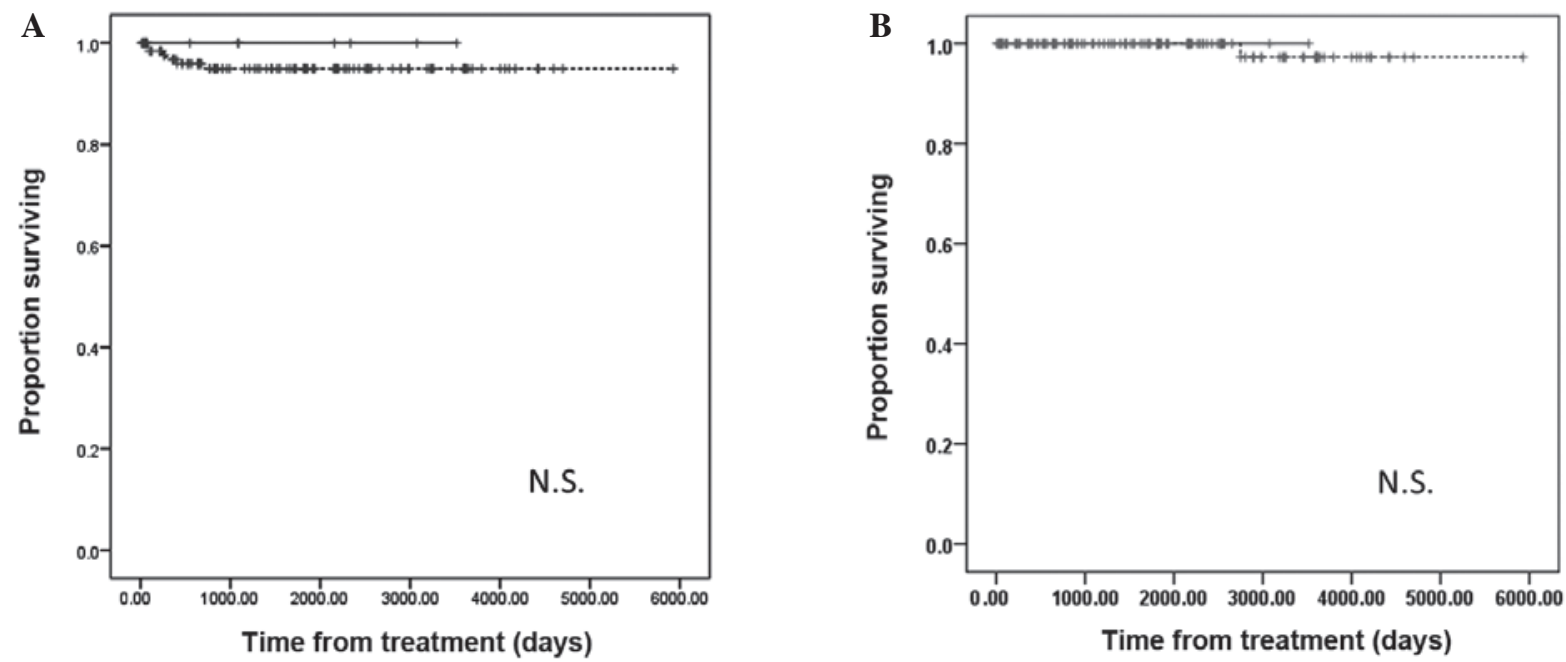

Figure 3. Kaplan-Meier estimates of patients with stage IA cervical cancer. (A) Disease-free survival; and (B) overall survival. Solid line, patients with cervical adenocarcinoma; and dashed line, patients with cervical squamous cell carcinoma.
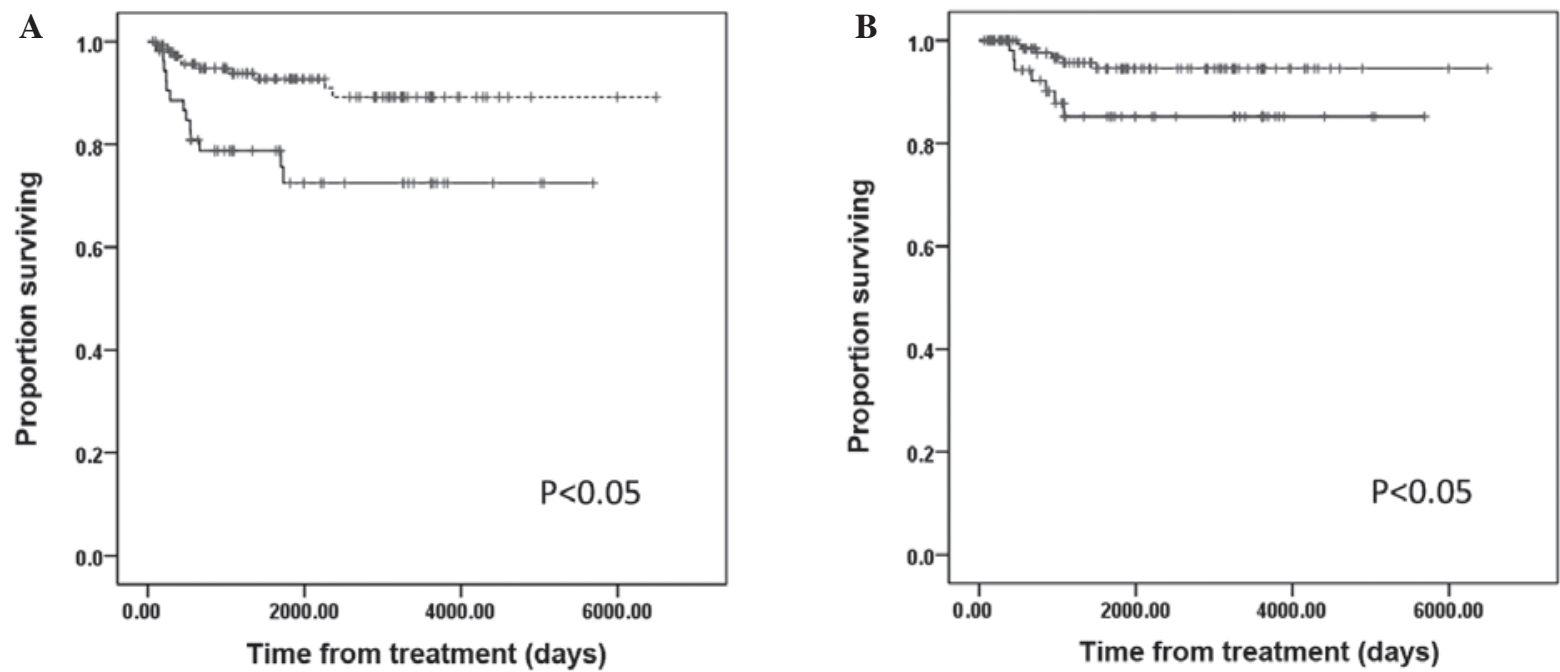

Figure 4. Kaplan-Meier estimates of patients with stage IB cervical cancer. (A) Disease-free survival; and (B) overall survival. Solid line, patients with cervical adenocarcinoma; and dashed line, patients with cervical squamous cell carcinoma. 

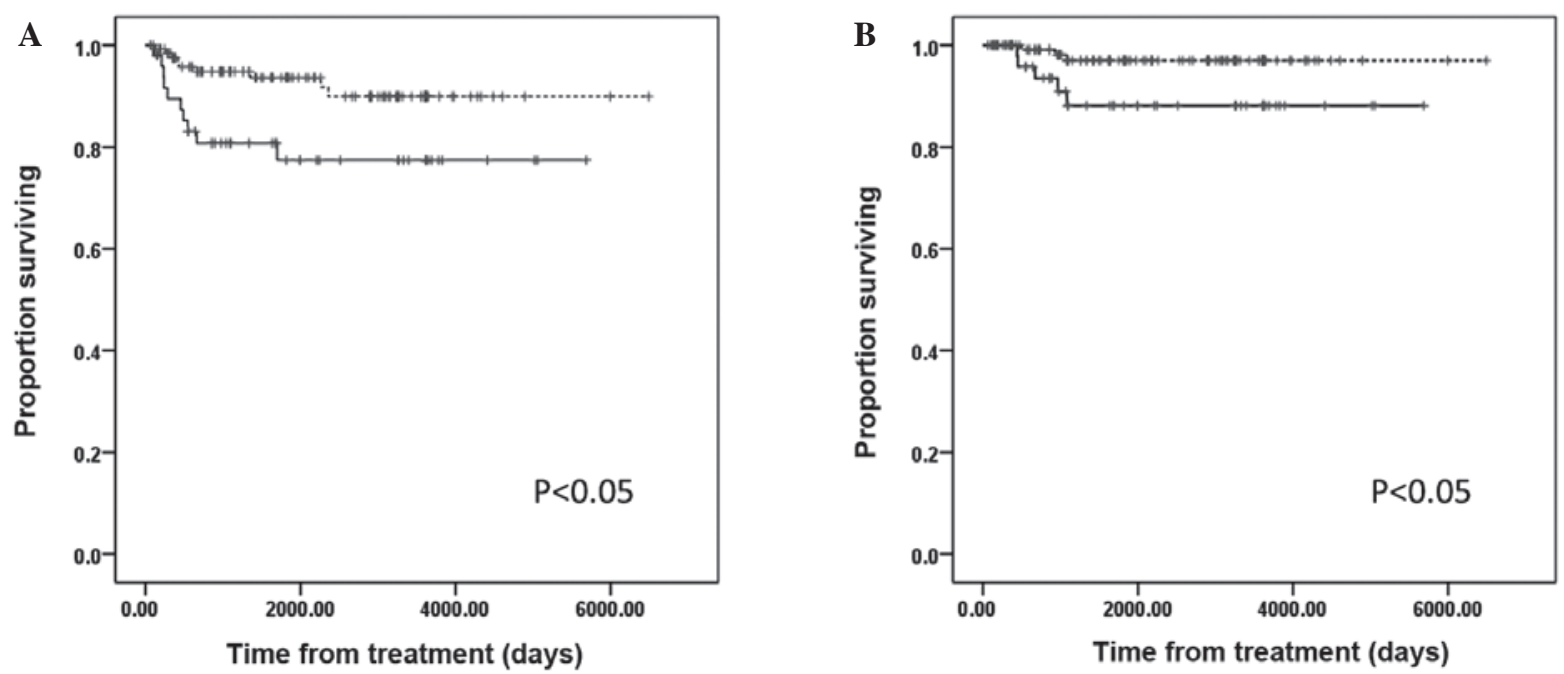

Figure 5. Kaplan-Meier estimates of patients with stage IA, node-negative cervical cancer. (A) Disease-free survival; and (B) overall survival. Solid line, patients with cervical adenocarcinoma; and dashed line, patients with cervical squamous cell carcinoma.
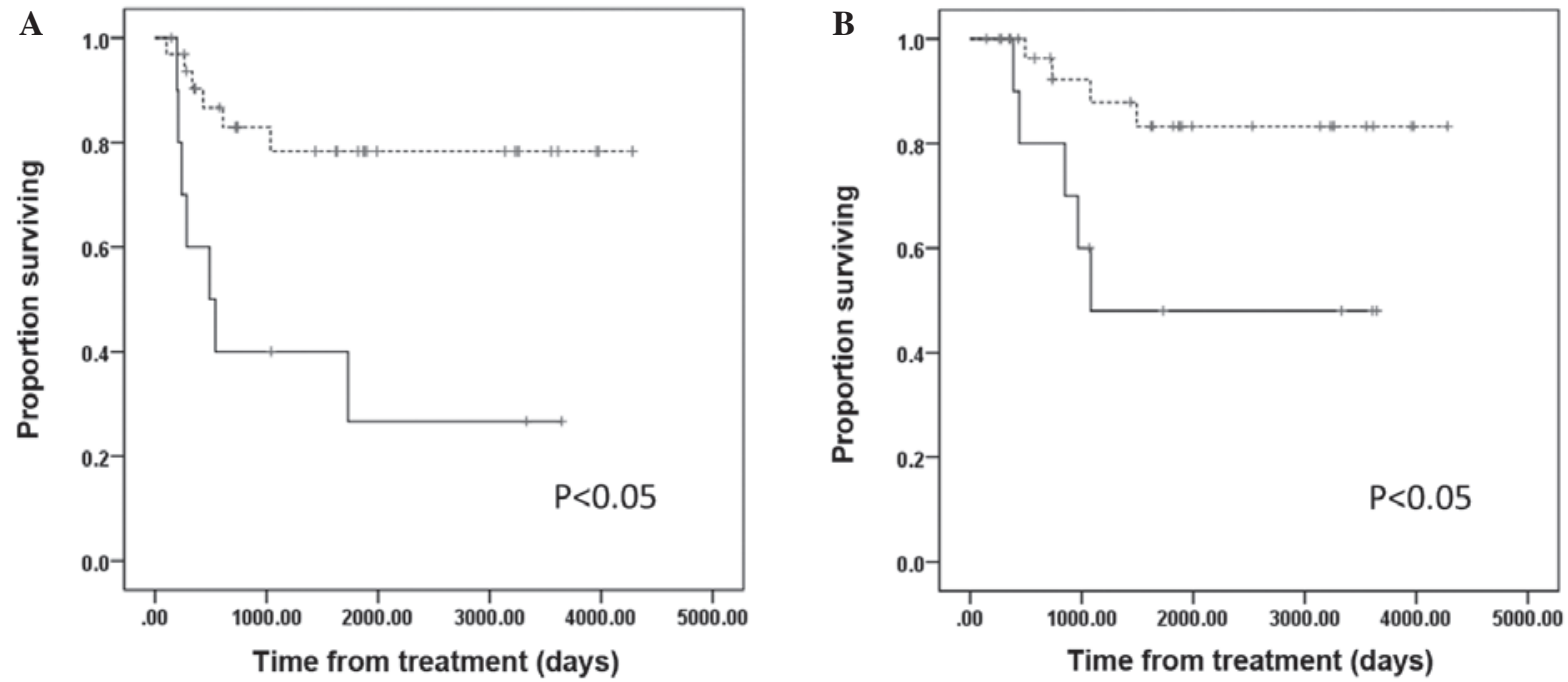

Figure 6. Kaplan-Meier estimates of patients who received postoperative treatment. (A) Disease-free survival; and (B) overall survival. Solid line, patients with cervical adenocarcinoma; and dashed line, patients with cervical squamous cell carcinoma.
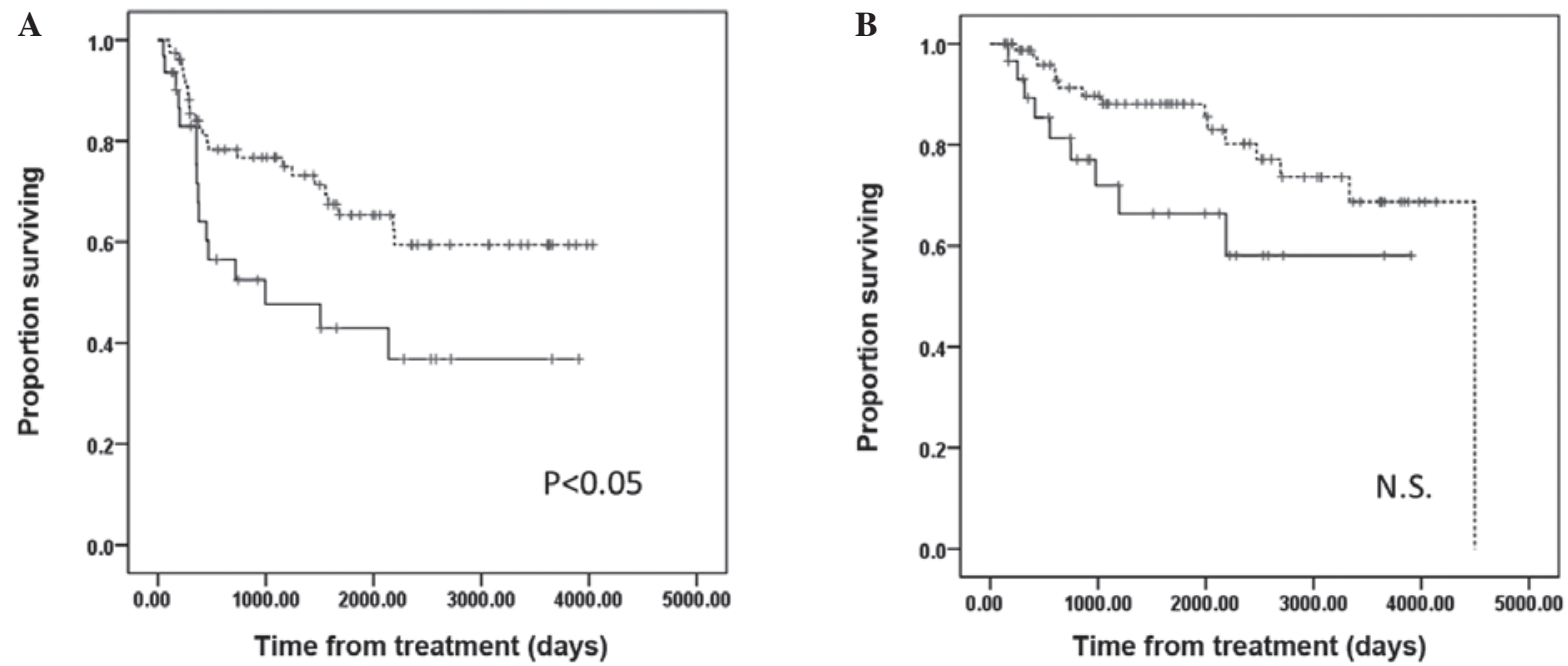

Figure 7. Kaplan-Meier estimates of patients with stage II cervical cancer. (A) Disease-free survival; and (B) overall survival. Solid line, patients with cervical adenocarcinoma; and dashed line, patients with cervical squamous cell carcinoma. 
Table II. Univariate and multivariate analyses of cervical adenocarcinoma.

\begin{tabular}{|c|c|c|c|c|c|c|}
\hline \multirow[b]{2}{*}{ Variables } & \multirow[b]{2}{*}{ No. of patients } & \multirow[b]{2}{*}{ 5-year survival (\%) } & \multirow{2}{*}{$\frac{\text { Univariate }}{\text { P-value }}$} & \multicolumn{3}{|c|}{ Multivariate } \\
\hline & & & & $\mathrm{RR}$ & $95 \% \mathrm{CI}$ & P-value \\
\hline Stage & & & 0.003 & & & NS \\
\hline $\mathrm{I} / \mathrm{II}$ & $60 / 31$ & $87 / 66$ & & & & \\
\hline Age, years & & & NS & & & NS \\
\hline$<40$ & 17 & 79 & & & & \\
\hline $40-65$ & 55 & 86 & & & & \\
\hline$>65$ & 19 & 65 & & & & \\
\hline Histological type & & & NS & & & NS \\
\hline Mucinous & 57 & 75 & & & & \\
\hline Endometrioid & 19 & 89 & & & & \\
\hline Adenosquamous & 11 & 90 & & & & \\
\hline Clear-cell & 3 & 100 & & & & \\
\hline Poorly differentiated & 1 & 100 & & & & \\
\hline Lymph node metastasis & & & $<0.001$ & & & NS \\
\hline No/yes & $25 / 66$ & $89 / 56$ & & & & \\
\hline LVSI & & & $<0.001$ & 4.8 & $1.5-15.4$ & 0.008 \\
\hline No/yes & $66 / 23$ & $85 / 51$ & & & & \\
\hline Cervical stromal invasion & & & $<0.001$ & 10.8 & $1.4-84.5$ & 0.024 \\
\hline$<$ half CW & 44 & 98 & & & & \\
\hline$\geq$ half CW & 45 & 61 & & & & \\
\hline Parametrial invasion & & & $<0.001$ & & & NS \\
\hline No/yes & $69 / 20$ & $90 / 45$ & & & & \\
\hline Vaginal invasion & & & 0.049 & & & NS \\
\hline No/yes & $81 / 8$ & $82 / 58$ & & & & \\
\hline Corpus invasion & & & 0.040 & & & NS \\
\hline No/yes & $69 / 20$ & $86 / 60$ & & & & \\
\hline Ovarian metastasis & & & 0.002 & 5.8 & $1.2-28.9$ & 0.032 \\
\hline No/yes & $85 / 4$ & $81 / 50$ & & & & \\
\hline Tumor diameter, mm & & & 0.017 & & & NS \\
\hline$\leq 40 />40$ & $70 / 19$ & $85 / 68$ & & & & \\
\hline
\end{tabular}

RR, relative risk; CI, confidence interval; NS, not significant; LVSI, lymphovascular space invasion; CW, cervical wall.
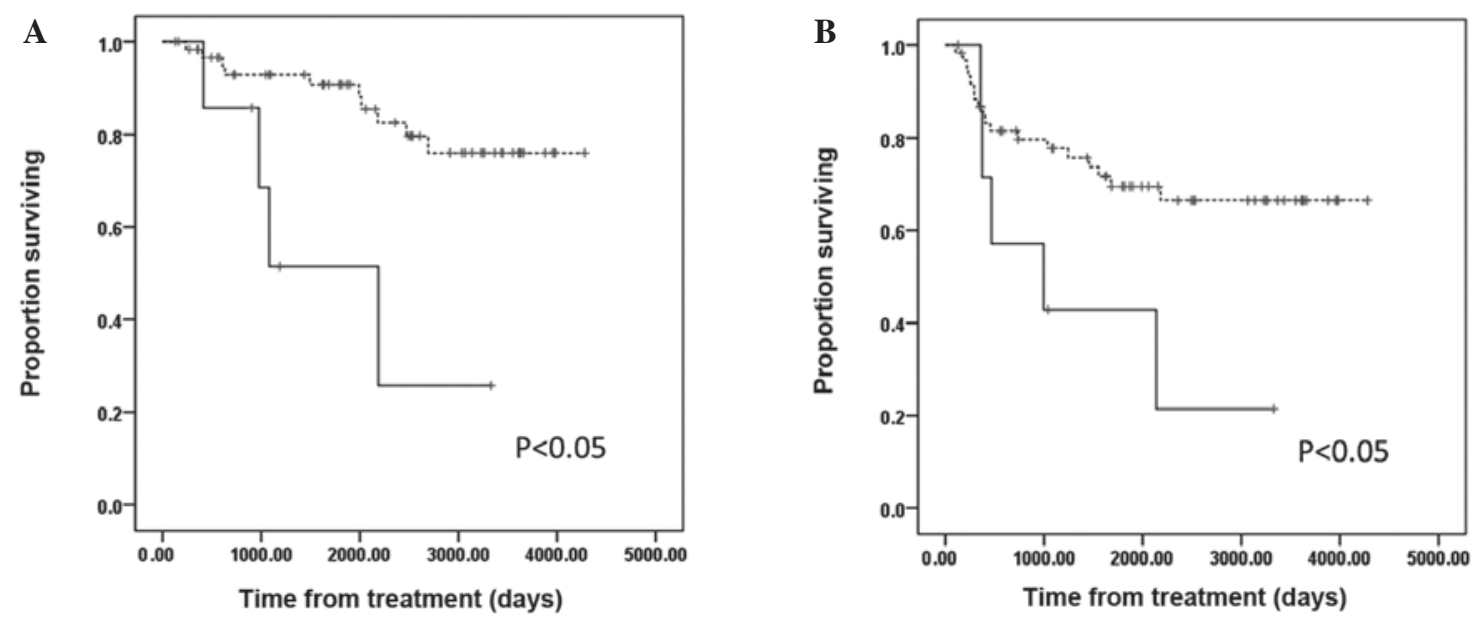

Figure 8. Kaplan-Meier estimates of patients who received postoperative irradiation alone. (A) Disease-free survival; and (B) overall survival. Solid line, patients with cervical adenocarcinoma; and dashed line, patients with cervical squamous cell carcinoma. 
Comparison of disease-free survival (DFS) and overall survival $(O S)$ between $A D$ and $S C C$. The OS and DFS of the AD group were poorer compared to those of the SCC group $(\mathrm{P}=0.01$ and $\mathrm{P}<0.001$, respectively; Fig. 1). The OS and DFS of stage I patients in the $\mathrm{AD}$ group were poorer compared to those of patients with stage I SCC ( $\mathrm{P}=0.01$ and $\mathrm{P}<0.001$, respectively; Fig. 2). The OS and DFS of stage IA patients did not significantly differ between the two groups (Fig. 3); however, the OS and DFS of stage IB patients with $\mathrm{AD}$ were poorer compared to those of stage IB patients with SCC ( $\mathrm{P}<0.05$ for both; Fig. 4). The OS and DFS of stage IA patients with node-negative $\mathrm{AD}$ were poorer compared to those of stage IA SCC patients $(\mathrm{P}<0.05$ for both; Fig. 5). The OS did not significantly differ between the two groups for patients with node-positive stage IB disease and for patients who did not receive postoperative treatment. However, patients with AD who received postoperative treatment exhibited significantly shorter OS and DFS ( $\mathrm{P}<0.05$ for both; Fig. 6).

Patients with stage II disease significantly differed regarding DFS, but not OS, between the two groups (Fig. 7). The effect of pelvic node status on prognosis did not significantly differ between the two groups. The OS and DFS of patients who received postoperative irradiation alone were shorter in the AD group compared to those in the SCC group $(\mathrm{P}<0.05$ for both; Fig. 8). The prognosis among all the patients who received postoperative chemotherapy did not differ between the two groups. Among patients who received postoperative CCRT, the OS did not differ significantly, but the DFS was significantly shorter in the AD group ( $\mathrm{P}<0.05$; data not shown).

Effects of clinicopathological factors on survival. The effects on the 5-year survival of the AD group by several clinicopathological variables are shown in Table II. In the univariate analysis, FIGO stage, lymph node metastasis, LVSI, cervical stromal invasion, parametrial invasion, vaginal invasion, corpus invasion, ovarian metastasis and tumor diameter significantly affected the 5-year survival in the AD group, whereas age and histological type did not. Stage I patients exhibited significantly better survival compared to stage II patients (87 vs. 66\%, respectively; $\mathrm{P}=0.003$ ). Patients without lymph node metastases had a 5-year survival of $89 \%$ compared to $56 \%$ in patients with positive lymph nodes $(\mathrm{P}<0.001)$. Among patients with LVSI, the 5-year survival rate was $51 \%$, whereas it was $85 \%$ in patients without LVSI $(\mathrm{P}<0.001)$. The depth of cervical stromal invasion significantly affected survival. When the stromal invasion depth was less than half of the cervical wall thickness, the 5-year survival was $98 \%$, whereas it was $61 \%$ when the invasion involved half or more of the cervical wall thickness $(\mathrm{P}<0.001)$. The 5-year survival in patients with and in those without parametrial invasion was 45 and $90 \%$, respectively $(\mathrm{P}<0.001) ; 58$ and $82 \%$ in those with and without vaginal invasion, respectively $(\mathrm{P}=0.049) ; 60$ and $86 \%$ in those with and without corpus invasion, respectively $(\mathrm{P}=0.040)$; and 50 and $81 \%$ in those with and without ovarian metastasis, respectively $(\mathrm{P}=0.002)$. The tumor diameter significantly affected survival; the 5-year survival rate was $85 \%$ for tumors with a diameter of $\leq 40 \mathrm{~mm}$ and $68 \%$ for those $>40 \mathrm{~mm}$ $(\mathrm{P}=0.017)$.

The multivariate analysis of cervical AD identified LVSI, stromal invasion and ovarian metastasis as independent prognostic factors.

\section{Discussion}

Over the last few years, the percentage of cervical AD has been increasing and reportedly now accounts for $21-25 \%$ of all cervical cancers (18-20); accordingly, AD comprised $20 \%$ of the cancers in this study.

The percentage of cases with FIGO stage IA in AD and SCC were 7.7 and $37.9 \%$, whereas those with FIGO stage IIB were 34.1 and $17.0 \%$, respectively. This indicates that patients with $\mathrm{AD}$ were detected later and diagnosed at more advanced stages. Investigations comparing the prognosis of cervical AD with SCC came up with varying results, with certain studies reporting AD to have a poorer prognosis compared to SCC (7-11) and others reporting no statistically significant differences between the two (12-16). Lymph node metastasis is commonly more aggressive in AD compared to SCC and some studies reported a higher incidence of lymph node metastasis and poorer prognosis in AD compared to SCC after controlling for stage and tumor size (22-24). However, although the rates of lymph node metastasis in our AD group (19\%) and SCC group (12.9\%) did not differ significantly, AD was significantly associated with a worse prognosis compared to $\mathrm{SCC}$ in all patients.

The effect of FIGO stage on prognosis varied. AD was significantly associated with worse prognosis compared to SCC only among patients with stage IB disease (particularly those who required postoperative treatment). Among patients who received postoperative irradiation alone, the AD group exhibited a significantly poorer prognosis compared to the SCC group; there was no significant difference between the two groups among patients who received postoperative chemotherapy or CCRT. These findings suggest that cervical AD is more radioresistant compared to SCC and support previous findings suggesting that postoperative irradiation alone does not improve OS in patients with cervical AD (25-27). Further studies are required to determine whether standard postoperative treatment after surgery for stage IB cervical AD should differ from that for SCC.

In conclusion, our results suggested that patients with cervical AD may have a poorer prognosis due to inadequate early detection. The multivariate analysis identified LVSI, stromal invasion and ovarian metastasis as independent predictors of shorter survival in patients with cervical AD. Stage IB AD was associated with a worse prognosis compared to stage IB SCC, particularly for patients who require postoperative treatment; such patients may benefit from individualized postoperative treatments that differ from those applied for SCC.

\section{References}

1. Jemal A, Bray F, Center MM, Ferlay J, Ward E and Forman D: Global cancer statistics. CA Cancer J Clin 61: 69-90, 2011.

2. Smith HO, Tiffany MF, Qualls CR and Key CR: The rising incidence of adenocarcinoma relative to squamous cell carcinoma of the uterine cervix in the United States - a 24-year population-based study. Gynecol Oncol 78: 97-105, 2000.

3. Schorge JO, Hossein Saboorian M, Hynan L and Ashfaq R: ThinPrep detection of cervical and endometrial adenocarcinoma: a retrospective cohort study. Cancer 96: 338-343, 2002.

4. McCluggage WG and Jenkins D: p16 immunoreactivity may assist in the distinction between endometrial and endocervical adenocarcinoma. Int J Gynecol Pathol 22: 231-235, 2003. 
5. Negri G, Egarter-Vigl E, Kasal A, Romano F, Haitel A and Mian C: p16INK4a is a useful marker for the diagnosis of adenocarcinoma of the cervix uteri and its precursors: an immunohistochemical study with immunocytochemical correlations. Am J Surg Pathol 27: 187-193, 2003.

6. Schorge JO, Knowles LM and Lea JS: Adenocarcinoma of the cervix. Curr Treat Options Oncol 5: 119-127, 2004.

7. Nakanishi T, Ishikawa H, Suzuki Y, Inoue T, Nakamura S and Kuzuya K: A comparison of prognoses of pathologic stage $\mathrm{Ib}$ adenocarcinoma and squamous cell carcinoma of the uterine cervix. Gynecol Oncol 79: 289-293, 2000.

8. Brand E, Berek JS and Hacker NF: Controversies in the management of cervical adenocarcinoma. Obstet Gynecol 71: 261-269, 1988.

9. Goodman HM, Buttlar CA, Niloff JM, Welch WR, Marck A, Feuer EJ, Lahman EA, Jenison EL and Knapp RC: Adenocarcinoma of the uterine cervix: prognostic factors and patterns of recurrence. Gynecol Oncol 33: 241-247, 1989.

10. Kim SM, Choi HS and Byun JS: Overall 5-year survival rate and prognostic factors in patients with stage IB and IIA cervical cancer treated by radical hysterectomy and pelvic lymph node dissection. Int J Gynecol Cancer 10: 305-312, 2000.

11. Park JY, Kim DY, Kim JH, Kim YM, Kim YT and Nam JH: Outcomes after radical hysterectomy in patients with early-stage adenocarcinoma of uterine cervix. Br J Cancer 102: 1692-1698, 2010.

12. Grisaru D, Covens A, Chapman B, Shaw P, Colgan T, Murphy J, DePetrillo D, Lickrish G, Laframboise S and Rosen B: Does histology influence prognosis in patients with early-stage cervical carcinoma? Cancer 92: 2999-3004, 2001.

13. Ayhan A, Al RA, Baykal C, Demirtas E, Yuce K and Ayhan A: A comparison of prognoses of FIGO stage IB adenocarcinoma and squamous cell carcinoma. Int J Gynecol Cancer 14: 279-285, 2004.

14. Lee KB, Lee JM, Park CY, Lee KB, Cho HY and Ha SY: What is the difference between squamous cell carcinoma and adenocarcinoma of the cervix? A matched case-control study. Int $\mathrm{J}$ Gynecol Cancer 16: 1569-1573, 2006.

15. Fregnani JH, Soares FA, Novik PR, Lopes A and Latorre MR: Comparison of biological behavior between early-stage adenocarcinoma and squamous cell carcinoma of the uterine cervix. Eur J Obstet Gynecol Reprod Biol 136: 215-223, 2008.
16. Kasamatsu T, Onda T, Sawada M, Kato T, Ikeda S, Sasajima Y and Tsuda H: Radical hysterectomy for FIGO stage I-IIB adenocarcinoma of the uterine cervix. Br J Cancer 100: 1400-1405, 2009.

17. Treatment guidelines for cervical cancer. Kanehara \& Co., Ltd. Japan Society of Gynecologic Oncology (eds). Tokyo, Japan, 2007 (In Japanese).

18. Hopkins MP and Morley GW: A comparison of adenocarcinoma and squamous cell carcinoma of the cervix. Obstet Gynecol 77: 912-917, 1991.

19. Harrison TA, Sevin BU, Koechli O, Nguyen HN, Averette HE, Penalver M, Donato DM and Nadji M: Adenosquamous carcinoma of the cervix: prognosis in early stage disease treated by radical hysterectomy. Gynecol Oncol 50: 310-315, 1993.

20. Anton-Culver H, Bloss JD, Bringman D, Lee-Feldstein A, DiSaia P and Manetta A: Comparison of adenocarcinoma and squamous cell carcinoma of the uterine cervix: a population-based epidemiologic study. Am J Obstet Gynecol 166: 1507-1514, 1992

21. Eifel PJ, Burke TW, Morris M and Smith TL: Adenocarcinoma as an independent risk factor for disease recurrence in patients with stage IB cervical carcinoma. Gynecol Oncol 59: 38-44, 1995.

22. Kleine W, Rau K, Schwoeorer D and Pfleiderer A: Prognosis of the adenocarcinoma of the cervix uteri: a comparative study. Gynecol Oncol 35: 145-149, 1989.

23. Moberg PJ, Einhorn N, Silfversward C and Soderberg G: Adenocarcinoma of the uterine cervix. Cancer 57: 407-410, 1986.

24. Alvarez RD, Soong SJ, Kinney WK, Reid GC, Schray MF, Podratz KC, Morley GW and Shingleton HM: Identification of prognostic factors and risk groups in patients found to have nodal metastasis at the time of radical hysterectomy for early-stage squamous carcinoma of the cervix. Gynecol Oncol 35: 130-135, 1989.

25. Soisson AP, Soper JT, Clarke-Pearson DL, Berchuck A, Montana G and Creasman WT: Adjuvant radiotherapy following radical hysterectomy for patients with stage IB and IIA cervical cancer. Gynecol Oncol 37: 390-395, 1990.

26. Landoni F, Maneo A, Colombo A, Placa F, Milani R, Perego P, Favini G, Ferri L and Mangioni C: Randomised study of radical surgery versus radiotherapy for stage Ib-IIa cervical cancer. Lancet 350: 535-540, 1997. 